\title{
Do European pharmacists really have to trespass on medicine?
}

\author{
Livio Garattini ${ }^{1} \cdot$ Anna Padula $^{1} \cdot$ Nicholas Freemantle $^{2}$
}

Received: 25 March 2020 / Accepted: 1 April 2020 / Published online: 11 April 2020

(c) Springer-Verlag GmbH Germany, part of Springer Nature 2020

\section{Introduction}

Pharmacy has been traditionally regarded as an intermediate discipline between health and chemistry [1], rooted in drug development, production, and compounding. The vast majority of pharmacists used to make drugs until the 1950s, no matter whether they worked in hospital or in community. These tasks have been almost lost with the large-scale manufacturing of pharmaceuticals by industry, and dispensing remains the main historical activity of pharmacists. In the long run, these changes have weakened the combination of the pharmacist's profession and education [2]. Although still focused on scientific subjects (for instance biology, chemistry, and physics), education has been inevitably affected by the domestic regulation of the profession, especially in the community domain, still by far the most important labor market for pharmacy graduates [3]. At present, pharmacy education has found a wide range of uneven solutions in European countries [2], starting from the shortest duration of graduation, which ranges from three (in Finland, Norway and Sweden) to six years (in France and The Netherlands) with Italy the only continental country that has lengthened the duration in recent decades from 4 to 5 years.

In the new millennium healthcare pharmacists have started claiming that the focus of their services-delivered as acknowledged drug therapy experts-has been increasingly shifted from the 'product' to the 'patient' regardless of where they work [4]. Switching the slogan from 'getting the right drug to each patient' to 'getting the drug therapy right for each patient' [5], both hospital and community pharmacists are expected to contribute increasingly to reduce clinical errors and ultimately improving the efficient use of health

Livio Garattini

livio.garattini@marionegri.it

1 Centre for Health Economics, Institute for Pharmacological Research Mario Negri IRCCS, Ranica, Italy

2 Institute of Clinical Trials and Methodology, University College London, London, UK care resources [6]. Clinical pharmacy and pharmaceutical care [7] are the two most cited concepts to back this trend.

Here, we first analyze the present role of pharmacists in hospital and community pharmacies. Then we summarize the narratives of clinical pharmacy and pharmaceutical care that support the tendency of pharmacists toward patient-centered care in the two settings. Finally, we envisage a possible future strategy for a common policy in the European Union (EU).

\section{Hospital and community pharmacists}

Hospital pharmacists are a historically recent profession that still includes only a minority of pharmacy graduates in Europe [8]. A patient's drug therapy can be divided into three steps in practice: prescription, distribution, and administration [9]. Traditionally, each of these steps can be easily ascribed to three classes of health professionals in the European hospitals-respectively physicians, pharmacists, and nurses [10]. According to the European Association of Hospital Pharmacists, hospital pharmacists are expected to perform (or at least supervise) drug ordering, purchasing, storage, and supply, even reviewing and validating all prescriptions if possible [11]. The supposed progression of the hospital pharmacist's professional role from simply moving boxes and handling supplies to provide clinical pharmacy services to patients should imply that seven 'rights' are always respected for all pharmaceutical therapies [11]: right patient, right dose, right route, right time, right drug, right information, and right documentation. The most recently debated argument in Europe is why hospital pharmacists should not be allowed to prescribe drugs, as already happens in other continents (e.g., Canada and the USA, Australia, and New Zealand) [9]. Although opposed by the medical profession from the outset, the right to prescribe in the EU is formally granted only in England and Ireland at present, not by chance countries where many hospital pharmacists are used to working in wards [12]. This move was probably favored by the recent shortage of physicians in these countries [10]. Besides requiring ample clinical knowledge (diagnostic 
skills included), the claim to extend prescribing rights is likely to bring hospital pharmacists - who are usually employees in their workplace-into conflict with their medical colleagues. Yet, the right to prescribe implies legal responsibility in case of clinical errors that many European hospital pharmacists would not necessarily be pleased to accept. This may involve legal litigations for negative outcomes with patients and their relatives, especially in the present era of 'defensive medicine' [13], potentially inducing high legal costs for accountable professionals [14].

Community pharmacists are the third largest group of healthcare professionals in the European Union (EU) after physicians and nurses [3]. The professional framework of European pharmacists in the community is very different from those in hospitals. Community pharmacies are predominantly private shops in almost all European countries [15], mainly owned either by a single pharmacist (like in France, Italy, and Spain) or a big chain (like in The Netherlands and the United Kingdom). As a consequence, commercial considerations are inevitably crucial for profitability. Overall, community pharmacists have always a potential conflict of interest when employed in a private pharmacy, due to their dual role of health professionals and commercial agents [15]. The clear evidence that commercial reasoning unavoidably prevails over the obligations of the health profession is the wide range of other products sold in the vast majority of pharmacies besides drugs, including some which should in fact conflict with pharmacist's education (e.g., homeopathic products). Professionally, most European community pharmacists are still responsible only for checking prescriptions. To our knowledge, the only (partial) exception in the EU is Dutch community pharmacists, who are allowed to intervene on prescriptions in case these do not respect national guidelines or do not seem suitable for an individual patient [16]. Conversely, Italian community pharmacists employed in para-pharmacies and health corners of large retail outlets-shops that are obliged to employ pharmacy graduates - are forbidden to dispense ethical medicines despite their degree, being only allowed to deliver over-thecounter drugs [17]. The only realistic excuse to justify this peculiar limit seems to be the defense of financial privileges matured by traditional community pharmacies, obligatorily owned by individual pharmacists who mostly inherit them [18]. This historical situation makes pharmacy lobbies perceive any legal change to the status quo as a potential 'Trojan horse' in favor of a market liberalization against traditional community pharmacies.

\section{Clinical pharmacy and pharmaceutical care}

Clinical pharmacy was originally defined as the area of pharmacy concerned with the science and practice of rational medication use [19]. Thanks to this health science discipline, pharmacists are expected to provide patient care that optimizes pharmaceutical therapies. Pharmaceutical care followed and was originally defined as the responsible provision of drug therapies for achieving definite outcomes that improve patients' quality of life [20]. The underlying recommendation was to move toward a patient-centered philosophy of clinical practice aimed at improving therapy outcomes. From its inception, the primary goal of pharmaceutical care was to give pharmacists the opportunity to move beyond the role of merely dispensing the right drug [21]. Later on, even the term itself was perceived as a limit against the spread of pharmaceutical care beyond the pharmacists' professional world [22].

Even though a recent survey evidenced that pharmaceutical care is mainly associated with community pharmacies in Europe [23], the two concepts are widely used and mixed in both primary and secondary care [7]. Therefore, despite various attempts to further define and differentiate them, clinical pharmacy and pharmaceutical care are still closely related and overlapping. Trying to achieve a synthesis, the practice of clinical pharmacy should embrace the philosophy of pharmaceutical care [19], the patient being the primary target for both of them.

From theory to practice, patient-centered care would require the pharmacist to advise patients directly for medication therapies and collaborate with the other healthcare professionals (especially physicians and nurses) in multidisciplinary teams [19]. Consistently with pharmaceutical care, the former activity would involve a narrative approach aimed at developing communication and empathy skills with patients, in order to cope with their emotional as well as health aspects [24]. This approach would also imply substantial changes in the classic training of pharmacy graduates.

The activity of collaboration with healthcare colleagues would imply providing additional patient-related services of clinical pharmacy [7]. In the light of the continuously growing numbers of elderly people, multimorbidities have become common in Europe and polypharmacy is an obvious consequence [4], with many patients taking five or more medicines daily. Therefore, medication review-a structured evaluation of a patient's medicine regimens with the aim of optimizing them and improving health outcomes [25] - has become a frequently cited concept in the literature, sort of 'umbrella term' including drug therapy adherence and reconciliation between medicines [26].

Although in theory, it seems realistic to expect positive results from clinical pharmacy services and pharmaceutical care philosophy [27], in practice, they are difficult to prove on the basis of clinical evidence. Many interventions are hard to standardize, hence their outcome measures in trials too $[9,15]$. Yet, most studies have been conducted on small samples in single facilities, probably pushed by pharmacists to demonstrate the usefulness of their local services; 
thus, results are hardly extendable to other hospital settings by definition. On account of the scant clinical evidence, cost-effectiveness analyses focused on arguable trade-offs between the additional costs of clinical pharmacy services and potential savings on other healthcare services can only add further confusion [28]. Besides the intrinsic limits of any economic evaluation in healthcare [29], these studies suffer from a poor methodological design [30] and seem to be often induced by a political objective to demonstrate the usefulness of the local services provided [31]. However, it goes without saying that any pharmacist can provide a good clinical service regardless of the healthcare setting, just like any other health professionals who do their jobs in the interests of patients.

\section{Future prospects}

The new wave of pharmacists' patient-centered care in the EU still seems to be a reaction against the demotion of their traditional role after the manufacturing revolution in the last millennium. Many statements sound like common sense, somehow masking a perceived identity crisis. To figure out a realistic scenario for a credible follow-on evolution of the pharmacist's role in health care, it is worth considering hospital and community as two very different settings in terms of healthcare policy.

Rather than arguably claiming prescription rights, hospital pharmacists could reinforce their role of pharmaceutical 'gatekeepers' to improve the appropriateness of prescriptions and eventually generate savings in pharmaceutical expenditure [32]. Being in the right position to advise prescribers as drug experts, European hospital pharmacists could strengthen their professional role by specializing in specific therapeutic areas of expertise (e.g., dermatology, neurology or oncology), affirming their independent opinions within multidisciplinary teams to enhance cost-effective prescribing in their hospitals. Once medical specialists have made their diagnosis and prescribed a drug therapy (if necessary), the selection of the most appropriate drug could be double-checked by hospital pharmacists. Hospital pharmacists could also question the preferred route of drug administration and/or drug form with problematic patients to favor their therapy adherence and help lighten the workload of their clinical colleagues. Finally, a further option for hospital pharmacists to extend their professional role might be to boost their knowledge on medical devices [9], a massive and heterogeneous class of products which are already part of their storage and supply work. Lacking specialists for these products in hospitals, teaching about clinical evidence of devices in master degrees for hospital pharmacy could be a useful opportunity to explore.
The proposal for clinical services provided by community pharmacists in the EU is unavoidably affected by the potential remuneration for private pharmacies. Although European community pharmacists are among the most easily accessible and highly visible healthcare professionals in primary care, most of them still work in small-to-medium shops that must ensure (high) returns on their investments [33]. This becomes paramount in countries (such as France, Italy, and Spain), where the 'one pharmacist-one pharmacy' rule still largely holds. The real marketing plus of pharmacies as shops is to attract additional customers for other products and services thanks to the monopoly on reimbursable drugs [15]. It would be useful to establish a systematic regulation for remuneration of both drug delivery and additional clinical services. Otherwise, pharmaceutical care risks remaining a disputable concept in practice, potentially driven by commercial incentives when intervening on prescriptions. For instance, this could be the case in a country like Italy where the remuneration for reimbursable drugs is still a (high) proportion of the price to the public, and not yet a (low) flat fee-unrelated to retail prices-for the dispensing service delivered as it has been for decades in the UK [34]. Last but not least, a minimum of three years to graduation should probably be enough for a pharmacist to start working in a community pharmacy and avoid feeling overqualified for her/his daily activities of dispensing drugs. By the way, this is the minimum duration in all European faculties except for human and veterinary medicine.

In conclusion, despite the permanent lack of political strength of the EU and its great weakness in this fieldinherited like in many others from a piecemeal national framework often backed by historically powerful lobbieswe are still fiercely convinced that European solutions are potentially the best in the long run. In this perspective, here we put forward a general proposal for updating the role of pharmacists in the European healthcare services to modern times, hopefully to re-open and refresh the debate.

Funding No sources of funding were used to conduct this study or prepare this manuscript.

\section{Compliance with ethical standards}

Conflict of interest Livio Garattini, Anna Padula and Nicholas Freemantle have no conflicts of interest directly relevant to this article.

\section{References}

1. Pearson, G.J.: Evolution in the practice of pharmacy—not a revolution! CMAJ 176(9), 1295-1296 (2007) 
2. Garattini, L., Padula, A.: From pharmacy faculty to pharmacy shop: still a logical pathway in Europe? Drugs Ther Perspect. 34(2), 85-88 (2018)

3. Mossialos, E., Courtin, E., Naci, H., Benrimoj, S., Bouvy, M., Farris, K., Noyce, P., Sketris, I.: From 'retailers' to health care providers: transforming the role of community pharmacists in chronic disease management. Health Policy 119, 628-639 (2015)

4. Moltó-Puigmartí, C., Vonk, R., van Ommeren, G., Hegger, I.: A logic model for pharmaceutical care. J Health Serv Res Policy. 23(3), 148-157 (2018)

5. Kehrer, J.P., Eberhart, G., Wing, M., Horon, K.: Pharmacy's role in a modern health continuum. Can Pharm J. 146(6), 321-324 (2013)

6. Atkinson, J.: The country profiles of the PHARMINE survey of european higher educational institutions delivering pharmacy education and training. Pharmacy (Basel). 5(3), E34 (2017)

7. Franklin, B.D., van Mil, J.W.: Defining clinical pharmacy and pharmaceutical care. Pharm World Sci 27(3), 137 (2005)

8. PHARMINE. Pharmacy Education In Europe. Countries profiles. Available from: https://www.pharmine.org/country-profiles/. Last accessed: December 2017.

9. Garattini, L., Padula, A.: Hospital pharmacists in Europe: between warehouse and prescription pad? Pharmacoecon Open. 2(3), 221224 (2018)

10. Surugue J, Vulto A. Workforce of EU hospitals and pharmacy services: a direct patient safety issue. EHJP Practice Fall 2006. Special Supplement. Available from: https://ec.europa.eu/health/archi ve/ph_systems/docs/ev_20080617_rd03_en.pdf. Last accessed: December 2017.

11. Anonymous. The European statements of hospital pharmacy. Eur J Hosp Pharm 2014;21:256-8.

12. Frontini, R., Miharija-Gala, T., Sykora, J.: EAHP survey 2010 on hospital pharmacy in Europe: parts 4 and 5 Clinical services and patient safety. Eur J Hosp Pharm 20, 69-73 (2013)

13. Garattini, L., Padula, A.: Defensive medicine in Europe: a 'full circle'? Eur J Health Econ. 21(2), 165-170 (2020)

14. Rothberg, M.B., Class, J., Bishop, T.F., Friderici, J., Kleppel, R., Lindenauer, P.K.: The cost of defensive medicine on three hospital medicine services. JAMA Intern Med. 174(11), 1867-1868 (2014)

15. Garattini, L., Padula, A.: Pharmaceutical care in Italy and other European countries: between care and commerce? Postgrad Med. 130(1), 52-54 (2018)

16. Teichert, M., Schoenmakers, T., Kylstra, N., et al.: Quality indicators for pharmaceutical care: a comprehensive set with national scores for Dutch community pharmacies. Int J Clin Pharm. 38(4), 870-879 (2016)

17. Garattini, L., van de Vooren, K., Curto, A.: Will the reform of community pharmacies in Italy be of benefit to patients or the Italian National Health Service? Drugs Ther Perspect. 28(11), 23-26 (2012)

18. Santuari, A.: Legal and organisational innovation in the Italian pharmacy system: commercial vs public interest. Health Econ Policy Law. 12(4), 495-513 (2017)

19. Anonymous. The definition of clinical pharmacy. American College of Clinical Pharmacy. Pharmacotherapy. 2008;28(6):816-7.

20. Hepler, C.D., Strand, L.M.: Opportunities and responsibilities in pharmaceutical care. Am J Hosp Pharm. 47(3), 533-543 (1990)
21. Babar ZU, Kousar R, Murtaza G, Azhar S, Khan SA, Curley L. Randomized controlled trials covering pharmaceutical care and medicines management: a systematic review of literature. Res Social Adm Pharm. 2017.pii: S1551-7411(17)30473-4.

22. Hill, P.: Pharmaceutical care RIP? Int J Pharm Pract. 20(1), 2-3 (2012)

23. Dreischulte, T., Fernandez-Llimos, F.: Current perceptions of the term clinical pharmacy and its relationship to pharmaceutical care: a survey of members of the European Society of Clinical Pharmacy. Int J Clin Pharm. 38(6), 1445-1446 (2016)

24. Naß, J., Banerjee, M., Efferth, T., Wohlmann, A.: Pharmaceutical care as narrative practice? Rethinking patient-centered care through a pharmacist's perspective. Int J Clin Pharm. 38(6), 1346-1349 (2016)

25. Griese-Mammen, N., Hersberger, K.E., Messerli, M., Leikola, S., Horvat, N., van Mil, J.W.F., Kos, M.: PCNE definition of medication review: reaching agreement. Int J Clin Pharm. 40(5), 1199-1208 (2018)

26. Blenkinsopp, A., Bond, C., Raynor, D.K.: Medication reviews. Br J Clin Pharmacol. 74(4), 573-580 (2012)

27. Lombardi, N., Wei, L., Ghaleb, M., Pasut, E., Leschiutta, S., Rossi, P., Troncon, M.G.: Evaluation of the implementation of a clinical pharmacy service on an acute internal medicine ward in Italy. BMC Health Serv Res. 18(1), 259 (2018)

28. De Rijdt, T., Willems, L., Simoens, S.: Hospital pharmacists versus hospital administrators: a struggle for clinical pharmacy services. Expert Rev Pharmacoecon Outcomes Res. 9(6), 497-498 (2009)

29. Garattini, L., Padula, A.: Dutch guidelines for economic evaluation: 'from good to better' in theory but further away from pharmaceuticals in practice? J R Soc Med. 110(3), 98-103 (2017)

30. Gallagher, J., McCarthy, S., Byrne, S.: Economic evaluations of clinical pharmacist interventions on hospital inpatients: a systematic review of recent literature. Int J Clin Pharm. 36(6), 1101-1114 (2014)

31. Campbell, G., Auyeung, V., McRobbie, D.: Clinical pharmacy services in a London hospital, have they changed? Int J Clin Pharm. 35(5), 688-691 (2013)

32. Garattini, L., Padula, A.: 'Appropriateness' in Italy: a 'magic word' in pharmaceuticals? Appl Health Econ Health Policy. 15(1), 1-3 (2017)

33. Soares, I.B., Imfeld-Isenegger, T.L., Makovec, U.N., Horvat, N., Kos, M., Arnet, I., Hersberger, K.E., Costa, F.A.: A survey to assess the availability, implementation rate and remuneration of pharmacist-led cognitive services throughout Europe. Res Social Adm Pharm. 16(1), 41-47 (2020)

34. Garattini, L., Curto, A., Padula, A.: Reimbursable drug classes and ceilings in Italy: why not only one? Eur J Health Econ. 17(8), 923-926 (2016)

Publisher's Note Springer Nature remains neutral with regard to jurisdictional claims in published maps and institutional affiliations. 